Canadian Science Publishing

Canadian Journal of Forest Research Revue canadienne de recherche forestière

\title{
Woody material structural degradation through decomposition on the forest floor
}

\begin{tabular}{|c|c|}
\hline Journal: & Canadian Journal of Forest Research \\
\hline Manuscript ID & cjfr-2017-0175.R2 \\
\hline Manuscript Type: & Note \\
\hline Date Submitted by the Author: & $10-$ Oct-2017 \\
\hline Complete List of Authors: & $\begin{array}{l}\text { Fraver, Shawn; University of Maine, School of Forest Resources } \\
\text { Tajvidi, Mehdi; University of Maine, School of Forest Resources } \\
\text { DAmato, Anthony; University of Vermont, Rubenstein School of } \\
\text { Environment and Natural Resources } \\
\text { Lindner, Daniel; US Department of Agriculture Forest Service, Northern } \\
\text { Research Station } \\
\text { Forrester, Jodi; North Carolina State University, Department of Forestry } \\
\text { and Environmental Resources } \\
\text { Milo, Amy; George Washington University, Biological Sciences ` }\end{array}$ \\
\hline Keyword: & carbon accounting, decay class, decay stakes, wood decay, woody debris \\
\hline $\begin{array}{r}\text { Is the invited manuscript for } \\
\text { consideration in a Special } \\
\text { Issue? : }\end{array}$ & N/A \\
\hline
\end{tabular}




\title{
Woody material structural degradation through decomposition on the forest floor
}

\author{
Shawn Fraver, Mehdi Tajvidi, Anthony W. D'Amato, Daniel L. Lindner, Jodi A. Forrester, and \\ Amy M. Milo
}

S. Fraver and M. Tajvidi. University of Maine, School of Forest Resources, 5755 Nutting Hall, Orono, Maine 04469, USA

A.W. D'Amato. Rubenstein School of Environment and Natural Resources, University of Vermont, 81 Carrigan Drive, Burlington, Vermont, 05405, USA

D.L. Lindner. USDA Forest Service, Northern Research Station, Center for Forest Mycology Research, Madison, Wisconsin 53726, USA

J.A. Forrester. Department of Forestry and Environmental Resources, North Carolina State University, Jordan Hall 3108, Raleigh, North Carolina 27695, USA

A.M. Milo. Department of Biological Sciences, George Washington University, Washington DC, USA 20052

Corresponding author: Shawn Fraver (email: shawn.fraver@maine.edu) 
27 Abstract: Dead woody material (DWM) plays numerous important roles in forest ecosystems;

28 however, through the process of decomposition, it undergoes structural and chemical changes

29 that progressively alter its function in these roles. Much remains unknown about how DWM

30 mechanical strength and structural integrity change through decomposition in natural forest

31 settings. We assessed changes in wood strength (bending strength, compressive strength, surface

32 hardness) using standard wood stakes of three species, for which initial mass was known, placed

33 in forested settings for two and four years before collection for laboratory analyses. All three

34 strength metrics decreased as stakes lost mass due to decay; however, bending strength had the

35 strongest relationship with mass loss, a result that was consistent for all species, as well as

36 species-pooled data. Results for all strength-loss metrics indicate that stakes had experienced ca.

$3710 \%$ strength loss before any detectable mass loss had occurred. Further, our results suggest that

38 the decay class system typically used during field inventories - based in large part on tactile

39 assessments of wood structural integrity - may provide a reasonable characterization of DWM

40 mass loss, which is a critical assumption for carbon accounting and modelling based on

41 inventory data.

42

43 Key words: Carbon accounting, decay class, decay stakes, forest fuels, wood decay, woody 44 debris 


\section{Introduction}

Dead woody material (DWM) plays a crucial role in forest ecosystems where it contributes to carbon storage, nutrient cycling, and biodiversity maintenance (Harmon et al. 1986, Stokland et al. 2012). However, as woody material decomposes, it undergoes structural and chemical changes that strongly influence its function in these roles. Progressive changes in wood mechanical strength, in particular, influence a number of ecological processes. For example, wood mechanical strength governs nest selection by cavity-nesting birds, such that their community structure depends on the distribution of trees containing zones of suitable hardness (Lorenz et al. 2015). Woody material strength is also closely related with foraging selection by bears, given that their food source (carpenter ants) is more likely to occur in logs of intermediate hardness (Frank et al. 2015). Similarly, the structural integrity and prevalence of internal voids in decaying wood dictate its use by Plethodontid salamanders for foraging and oviposition (Heatwole 1962) and influences the likelihood of stem breakage in snags (Angers et al. 2010).

Wood loses mechanical strength through decomposition as the structural components of cell walls - lignin, cellulose, and hemicellulose - are progressively degraded by fungi. Insects hasten structural degradation by introducing additional decomposing microbes and creating internal voids (Harmon et al. 1986). Several recent studies have shown various metrics of wood strength to be sensitive indicators of decay in natural forest settings (Larjavaara and MullerLandau 2010, Oberle et al. 2014); in fact, in the earliest stages of decay, reduction in mechanical strength may occur before measurable reductions in wood mass (Curling et al. 2002, Venäläinen et al. 2014). 
Despite the large body of research addressing dead woody material (DWD) in recent

70 decades (Russell et al. 2015), much remains unknown about the changes in DWM strength and

71 structural integrity through decomposition in natural forest settings. This knowledge gap is

72 especially important given that the criteria for assigning decay classes (evaluation of how far

73 decay has advanced; Sollins 1982) during forest inventories rely in large part on field

74 assessments of wood strength (Woodall and Monleon 2008). It also has relevance in the context

75 of post-disturbance salvage logging operations, given that wood may partially degrade, and thus

76 lose value, before salvage operations can commence (Ruel et al. 2010). Thus our objectives were

77 to (1) assess changes in wood mechanical strength (i.e., bending strength, compressive strength,

78 surface hardness) caused by decomposition on the forest floor, and (2) test the relationship

79 between these strength metrics and mass loss, a critical metric used in ecological studies,

80 including forest carbon accounting and modelling. We accomplished these objectives by using

81 standard wood stakes of three common tree species, for which initial density and dry mass were

82 known, deployed in natural forest settings (in the US Lake States) for two to four years before

83 collection for laboratory analyses.

84 Wood mechanical strength loss owing to fungal decay is well known in the forest

85 products literature (e.g., Brischke et al. 2008, Witomski et al. 2016). Such studies typically

86 involve inoculation of sound wood with selected fungi, followed by laboratory incubation for

87 specified periods and ultimately strength tests (Witomski et al. 2016). Our study differs in that

88 wood samples were placed in natural forest settings and thus were colonized by a range of

89 resident wood-decay fungi known from these sites (Brazee et al. 2012, 2014).

90

91 


\section{Study design}

The sites used in this study are part of a larger experiment aimed at assessing the impacts

95 of intensive biofuels harvesting on site productivity and nutrient cycling (see Kurth et al. 2014). As part of that study, ca. 1400 decay stakes - standard-sized wood stakes, for which initial

97 density and dry mass were known - of three species were placed in various sites and treatments to assess variability in stake decay rates as a function of site conditions and local fungal communities. Sites and treatments included a continuum of open- to closed-canopy conditions, creating a range of moisture and light availability; for details see Kurth et al. (2014) and Brazee et al. (2014). Multiple stakes at each site-treatment locations were deployed in 2010, with the intent of collecting subsets of them at two-year intervals over eight years. Study sites are located in northern Minnesota and northern Wisconsin, USA.

Stakes were manufactured to $2.54 \times 2.54 \times 20 \mathrm{~cm}$ from locally harvested balsam fir

111 (Wisconsin).

(Abies balsamea) and aspen (Populus tremuloides) for the Minnesota sites and from sugar maple (Acer saccharum) for the Wisconsin sites, representing the common overstory tree species for each location. Only select, knot- and defect-free wood was used. Before being deployed, all stakes were oven dried for 8 days at $75 \square \mathrm{C}$ to achieve constant mass (Fraver et al. 2013), and each was weighed while dry. Each stake was uniquely numbered and tagged. Stakes were placed on the forest floor on permanently monumented plots in June 2010 (Minnesota) and July 2010 
115 permanent sample plots), and at one site in Wisconsin (Flambeau State Forest) we used a similar 116 sample size of 33 stakes of Acer saccharum. In addition, 10 non-decayed stakes of each species,

117 randomly chosen from the complete pool of stakes, were initially set aside for strength tests.

118 Sample sizes were chosen to provide adequate confidence in our estimates of strength loss, based 119 on data presented in Jurgensen et al. (2006). Analyses of variance revealed that the initial

120 densities, within a species, did not differ significantly between the deployed and non-deployed 121 stakes (tested at $\alpha=0.05$ ). Stakes used in this study were collected in early July of 2012 and 122 2014, that is, after two and four years of decay on the forest floor. Samples were limited to this 123 four year period because as decay advances, pieces become irregular in shape and lose volume 124 (Fraver et al. 2013), making them unsuitable for use on the testing equipment (below), which 125 requires samples of uniform size. Indeed, several samples had deformities making them 126 admittedly less than ideal for these tests; we return to this topic in the Results and discussion. In 127 the laboratory, stakes were cleaned of soil and debris and oven dried for 8 days at $75 \square \mathrm{C}$ before 128 being weighed. Stakes were kept at equilibrium humidity and temperature for at least two weeks 129 prior to the strength tests that followed.

\section{Strength tests and analyses}

We selected three wood strength tests - static bending, compression perpendicular to 133 grain, and surface hardness - intended to best represent the range of tactile criteria typically 134 employed in field inventories of woody material. The tests are described here in the order in 135 which they were performed on each decay stake. Center-loading static bending (flexure) tests, 136 with samples centered in the test machine (using the entire stakes), were conducted with supports 137 spanning $16.5 \mathrm{~cm}$, resulting in modulus of rupture (MOR, a measure of stress required to cause 
138 139

failure) for each sample. Though this span distance differs from the American Society for Testing and Materials standard (14 inches, or $35.6 \mathrm{~cm}$ ) (ASTM, 2014), it allows comparisons of the relative flexural strength across these samples. Compression tests were conducted using a $2.54 \times$ $2.54 \mathrm{~cm}$ plane compression platen, recording a stress at proportional limit for each test, which depicts the greatest force the stake can withstand before losing shape. Surface hardness tests were conducted using the Janka method, which measures the force required to embed a small steel sphere (11.3 mm diameter) half way into the sample (Green et al. 2006). Two compression tests and two surface hardness tests were conducted for each stake choosing portions of the stake unaffected by the static bending fracture and least affected by decay-related deformities, rotating the stake $90 \square$ radially, with results averaged for each stake (Hoadley 2000, Green et al. 2006). All tests were conducted on an Instron ${ }^{\circledR}$ (Model 4202) system, using forces applied at 2.54 $\mathrm{mm} / \mathrm{minute}$ (flexure and surface hardness) and $5.0 \mathrm{~mm} /$ minute (compression test).

For analysis, we expressed the three strength metrics as percent reductions relative to the mean of non-decayed samples, and we expressed mass loss as a percentage relative to the stake's initial dry mass before deployment. Following Jurgensen et al. (2006) we chose to analyze the non-transformed percentages because we were particularly interested in the value of the intercepts. Expressing these measures as percentages also allowed us to combine the analyses for the three species, which have rather different properties when expressed in absolute terms. We used non-linear mixed-effects models to assess the relationship between strength-loss metrics (the response variables) and mass loss, for a total of three tests. Initial screening of linear and three candidate non-linear models using Akaike's corrected information criterion (AICc) indicated that a power function $\left(\mathrm{y}=a \bullet \mathrm{x}^{b}\right)$ was best supported by data for all three strength metrics, using the pooled data. Species was treated as a random effect in these models, allowing 
161 a random intercept. In addition, we analyzed the relationship between strength loss metrics and

162 mass loss separately by species, also using the power function model form. All models were

163 evaluated in the nlme package (Pinheiro et al., 2016) for R (R Core Team, 2016). Goodness-of-fit

164 (pseudo $\mathrm{R}^{2}$ ) was expressed as the correlation between observed and predicted strength reductions

165 (cf. Canham et al. 2004).

166

167 Results and discussion

168

169

170

All three strength-loss metrics showed strong positive relationships with mass loss for each species as well as species-pooled data (Fig. 1, Table 1). Similar findings using decay stakes

171 in forested settings have been reported (Jurgensen et al. 2006, González et al. 2008). Our

172 findings suggest that bending strength had the strongest relationship with mass loss for each

173 species individually, as well as for the pooled data (Table $1, R^{2}$ values). For the pooled data,

174 bending strength had an $R^{2}$ of 0.860 , followed by surface hardness $\left(R^{2}=0.824\right)$ and compressive

175 strength $\left(R^{2}=0.718\right)$ (Table 1, Fig. 1). In contrast to our findings, Jurgensen et al. (2006) found

176 that radial compressive strength better represented mass loss, when compared to surface hardness

177 or longitudinal shear. This contrasting result might be explained by the greater range of densities

178 represented by our three species, when compared to the two used by Jurgensen et al. (2006).

All individual species models as well as species-pooled models from the three strength

180 metrics had positive intercepts, indicating that stakes had lost strength before any detectable

181 mass loss had occurred (Fig. 1, Table 1). For the pooled data, these intercepts were 13.7, 7.2 and

1826.9 (bending strength, compressive strength, and surface hardness, respectively). This finding has

183 been previously reported from laboratory incubation studies (Curling et al. 2002, Venäläinen et 
184 al. 2014), as well as a field trial similar to our own (Jurgensen et al. 2006). In fact, the latter 185 study reports a ca. 9\% loss in compressive strength before detectable mass loss, a value quite 186 close to our estimate of 7.2\% (above). Curling et al. (2002) conclude that the initial strength loss 187 results from the fungal degradation, but not consumption, of the galactan and arabinan 188 189 190 components of hemicellulose. Although these findings may suggest that strength tests could be used to assess incipient wood decay in situations where rapid estimates of decay are needed (Jurgensen et al. 2006) or when assessing species with inherently slow decay, we caution that early strength loss rates do not necessarily translate to higher decay rates (i.e., mass loss) over 192 longer time periods. We recommend additional research on this topic, as a demonstrated strong 193 relationship between early strength reduction and long-term decay rates would be quite

194 beneficial (in terms of time efficiency) in studies addressing controls of wood decay. Properly 195 addressing this topic would require strength tests using a large number of species (capturing a range of functional traits) and spanning a range of initial decays. tremuloides, and were moderately correlated within Abies balsamea (Table 2), suggesting that 199 decay affected various aspects of strength in similar ways and implying that any of these metrics could function reasonably well as indicators of decay progression within a species. 
207

208

209

210

211

212

213

214

215

216

217

218

219

220

221

222

223

224

225

226

227

228

229

unacceptable for testing commercial forest products, we allowed ourselves flexibility in this regard, reasoning that we could not simultaneously use partially decayed material (the objective of our study) and have perfectly preserved samples. Interestingly, the vast majority of deformed samples were those of Populus tremuloides, the species that ultimately showed the strongest relationship between strength loss and mass loss for two of the three strength metrics. We note too that, unlike bending strength, the compressive strength and surface hardness tests were conducted at specific stake locations and thus may not capture the variability within the entire stake. The uncertainty thus introduced could partially explain the poorer model fit (lower regression $R^{2}$, Table 1) for these metrics when compared to that of bending strength. Although our intent was not to compare species, we note that the conifer species (Abies balsamea) showed the least strength loss (all three metrics) and the least mass loss when compared to the hardwood species (Fig. 1). This finding reflects the fact that conifers generally decay more slowly than hardwoods, despite their lower initial wood densities (Russel et al. 2014), which is often attributed to higher concentrations of extractives in softwoods. Mechanical strength of dead woody material (DWM) has important implications for interpreting and processing forest inventory data, particularly for estimating forest biomass and carbon stocks. During DWM field inventories, decay classes are assigned to each DWM piece to depict how far decay has advanced (Sollins 1982). The various field protocols for assigning decay classes include tactile assessments of wood strength and structural integrity, such as surface hardness (Maser et al. 1979), the depth a sharp object can penetrate the log (Larjavaara and Muller-Landau 2010, Jacobs and Work 2012), the ability of the piece to hold its own weight (Sollins 1982, Stokland et al. 2012), and resistance to forced breakage (Larjavaara and MullerLandau 2010). Decay classes thus assigned are used to convert field-measured DWM volumes to 
230 biomass, using published decay-class- and species-specific density reduction factors (e.g.,

231 Harmon et al. 2008), reflecting the fact that DWM mass diminishes as decomposition advances.

232 Although we were unable to assign decay classes to our samples (the criteria also include

233 characteristics such as bark features and cross-sectional shape that do not apply to our stakes),

234 our results suggest that the wood strength loss, as assessed by the decay-class system, may

235 provide a reasonable characterization of mass loss, which is a critical assumption for carbon

236 accounting and carbon modelling based on field inventory data (Fraver et al. 2013).

Strength loss following tree death also has relevance in the context of post-disturbance

238 salvage logging operations, given that wood may partially degrade, and thus lose value, before

239 salvage operations can commence. Ruel et al. (2010) found that static bending became variable

240 for Abies balsamea and was reduced for Picea mariana (black spruce) logs that had remained on

241 site for four years after windthrow. Somewhat similarly, Mocham (2002) found gradual declines

242 in bending strength the longer windthrown Picea sitchensis (Sitka spruce) trees were left on site,

243 for up to three years. Our results show significant reductions in static bending for all three

244 species tested after two years, with further reductions at year four only for Acer saccharum (not

245 shown). We note that unlike the two studies mentioned above, our samples were located directly

246 on the forest floor (not partially elevated following windthrow), which would have increased

247 their moisture content and hastened their decay (Næsset 1999). Their small size, relative the

248 material used in the studies mentioned above, as well as the lack of bark, also likely contributed

249 to more rapid decay and accompanying strength loss.

250 Our study adds to the growing number of decay-stake experiments worldwide that are

251 providing insights into aspects of wood decomposition that had been previously

252 underappreciated. For example, Bradford et al. (2014) demonstrated the greater importance of 
253 local drivers such as fungi and termites, relative to regional climatic factors, in governing wood 254 decay rates in eastern US forests. Similarly, Meier et al. (2014) pointed to the strong influence of 255 fungal richness and community composition, as well as temperature, in controlling wood decay 256 rates in the Peruvian Andes, and Risch et al. (2013) demonstrated the importance of land use on 257 wood decay rates, presumably through altered temperature regimes, in central Europe. Crockatt 258 and Bebber (2014) reported that decay rates increased along a forest edge-to-interior gradient, 259 following a similar gradient of increasing moisture; González et al. (2008) reported a similar 260 positive influence of moisture on wood decay rates in boreal and temperate forests.

In summary, our study demonstrates that the three strength metrics were moderately to 262 strongly correlated with each other over the range of decay found in our samples. Reductions in 263 all three metrics closely paralleled reductions in wood mass, consistent with findings of 264 Jurgensen et al. (2006) and González et al. (2008). Our results suggest that the wood strength 265 assessments - similar to the ones tested here - employed in decay-class systems may provide a 266 reasonable characterization of mass loss from decaying wood in natural forest settings, which is 267 a critical assumption for carbon accounting based on inventory data.

\section{Acknowledgements}

271 We thank M. Curzon, J. Kragthorpe, C. Kuehne, M. Russell, R. Seavey, T. Smith, and A.

272 Teets for assistance in the laboratory or field. Comments from K. Costanza and three anonymous 273 reviewers substantially improved the manuscript. This work was improved through discussions 274 with B. Oberle. This project was supported by the USDA/DOE Biomass Research and 
275 Development Initiative (\#2009-10006-05948), the Minnesota Environment and Natural

276 Resources Trust Fund, and the Minnesota Forest Resources Council.

277

278

279 
280

281

282

283

284

285

286

287

288

289

290

291

292

293

294

295

296

297

298

299

300

301

302

\section{References}

ASTM (American Society for Testing and Materials). 2014. Standard test methods for small clear specimens of timber, D143-14. ASTM International, West Conshohocken, Pennsylvania, USA.

Angers, V.A., Drapeau, P. and Bergeron, Y. 2010. Snag degradation pathways of four North American boreal tree species. For. Ecol. Manage. 259(3): 246-256.

Bradford, M.A., Warren R.J. II, Baldrian, P., Crowther, T.W., Maynard, D.S., Oldfield, E.E., Wieder, W.R., Wood, S.A, and King, J.R. 2014. Climate fails to predict wood decomposition at regional scales. Nat. Clim. Change 4(7): 625-630.

Brazee, N., Lindner, D.L., Fraver, S., D'Amato A.W., and Milo, A.M. 2012. Wood-inhabiting, polyporoid fungi in aspen-dominated forests managed for biomass in the U.S. Lake States. Fungal Ecol. 5: 600-609.

Brazee, N., Lindner, D.L., D'Amato, A.W., Fraver, S., Forrester, J.A., and Mladenoff, D.J. 2014. Disturbance and diversity of wood-inhabiting fungi: effects of canopy gaps and downed woody debris. Biodivers. Conserv. 23: 2155-2172.

Brischke, C., Welzbacher, C.R. and Huckfeldt, T. 2008. Influence of fungal decay by different basidiomycetes on the structural integrity of Norway spruce wood. Eur. J. Wood Wood Prod. 66(6): 433-438. Canham, C.D., LePage, P.T., and Coates, K.D. 2004. A neighborhood analysis of canopy tree competition: effects of shading versus crowding. Can. J. For. Res. 34: 778-787.

Crockatt, M.E., and Bebber, D.P. 2015. Edge effects on moisture reduce wood decomposition rate in a temperate forest. Global Change Biol. 21(2): 698-707. 
Curling, S.F., Clausen, C.A, and Winandy, F.E. 2002. Relationships between mechanical properties, weight loss, and chemical composition of wood during incipient brown-rot decay. Forest Prod. J. 52(7-8): 34-39.

Frank, S.C., Steyaert, S.M., Swenson, J.E., Storch, I., Kindberg, J., Barck, H. and Zedrosser, A. 2015. A "clearcut" case? Brown bear selection of coarse woody debris and carpenter ants on clearcuts. For. Ecol. Manage. 348: 164-173.

Fraver, S., Milo, A.M., Bradford, J.B., D’Amato, A.W., Kenefic, L., Palik, B.J., Woodall, C.W., and Brissette, J. 2013. Woody debris volume depletion through decay: Implications for biomass and carbon accounting. Ecosystems 16(7): 1262-1272.

González, G., Gould, W.A., Hudak, A.T., and Hollingsworth T.N. 2008. Decay of aspen (Populus tremuloides Michx.) wood in moist and dry boreal, temperate, and tropical forest fragments. AMBIO 37(7-8): 588-597.

Green, D.W., Begel, M., and Nelson, W. 2006. Janka hardness using nonstandard specimens. USDA Forest Service, Forest Products Laboratory, Madison, Wisconsin. Research Note FPL RN-0303.

Harmon, M.E., Franklin, J.F., Swanson, F.J., Sollins, P., Gregory, S.V., Lattin, J.D., Anderson, N.H., Cline, S.P., Aumen, N.G., Sedell, J.R., Lienkaemper, G.W., Cromack, K. Jr., and Cummins, K.W. 1986. Ecology of coarse woody debris in temperate ecosystems. Adv. Ecol. Res. 15: 133-302.

Harmon, M.E., Woodall, C.W., Fasth, B., and Sexton J. 2008. Woody detritus density and density reduction factors for tree species in the Unitied States: A synthesis. USDA Forest Service, Northern Research Station, Gen. Tech. Rep. NRS-29. 
325 Heatwole, H. 1962. Environmental factors influencing the local distribution and activity of the 326 salamander, Plethodon cinereus. Ecol. 43: 460-472.

327 Hoadley, B.R. 2000. Understanding wood: A craftsman's guide to wood technology. The Taunton $328 \quad$ Press, Newtown, Connecticut, USA.

329 Hyde, J.C., Smith, A.M., Ottmar, R.D., Alvarado, E.C., and Morgan, P. 2011. The combustion of 330 sound and rotten coarse woody debris: a review. Int. J. Wildland Fire 20(2): 163-174.

331 Jacobs, J.M., and Work, T.T. 2012. Linking deadwood-associated beetles and fungi with wood 332 decomposition rates in managed black spruce forests. Can. J. For. Res. 42(8): 1477-1490.

333 Jurgensen, M., Reed, D., Page-Dumroese, D., Laks, P., Collins, A., Mroz, G., and Degórski, M. 334 2006. Wood strength loss as a measure of decomposition in northern forest mineral soil. Eur. 335 J. Soil Biol. 42(1): 23-31.

336 Kurth, V.J., Bradford, J.B., Slesak, R.A., and D’Amato, A.W. 2014. Initial soil respiration 337 response to biomass harvesting and green-tree retention in aspen-dominated forests of the 338 Great Lakes region. For. Ecol. Manage. 328: 342-352.

339 Larjavaara, M., and Muller-Landau, H.C. 2010. Comparison of decay classification, knife test, 340 and two penetrometers for estimating wood density of coarse woody debris. Can. J. For. Res. $341 \quad 40: 2313-2321$.

342 Lorenz, T.J., Vierling, K.T., Johnson, T.R. and Fischer, P.C. 2015. The role of wood hardness in 343 limiting nest site selection in avian cavity excavators. Ecol. Appl. 25(4): 1016-1033.

344 Maser, C., Anderson, R.G., Cromack, K. Jr., Williams, J.T., and Martin, R.E. 1979. Dead and 345 down woody material. In Wildlife habitats in managed forests: the Blue Mountains of Oregon 346 and Washington. Edited by J.W. Thomas. USDA Forest Service Agric. Handb. 553. pp. 7834795. 
348 349

Meier, C.L., Rapp, J., Bowers, R.M., Silman, M., and Fierer, N. 2010. Fungal growth on a common wood substrate across a tropical elevation gradient: Temperature sensitivity, community composition, and potential for above-ground decomposition. Soil Biol. Biochem. 42: $1083-1090$.

Mochan, S. 2002. The effect of windblow on timber quality in Sitka spruce. M.Sc. thesis, University of Edinburgh, Scotland.

Næsset E. 1999. Decomposition rate constants of Picea abies logs in southeastern Norway. Can. J. For. Res. 29: 372-81.

Oberle, B., Dunham, K., Milo, A.M., Walton, M., Young, D.F., and Zanne, A.E. 2014. Progressive, idiosyncratic changes in wood hardness during decay: Implications for dead wood inventory and cycling. For. Ecol. Manage. 323: 1-9.

Pinheiro, J., Bates, D., DebRoy, S., and Sarkar, D. 2016. nlme: Linear and nonlinear mixed effects models. URL CRAN. R-project.

R Core Team, 2016. R: A language and environment for statistical computing. R Foundation for Statistical Computing, Vienna, Austria.

Risch, A.C., Jurgensen, M.F., Page-Dumroese, D.S., and Schütz, M. 2013. Initial turnover rates of two standard wood substrates following land-use change in subalpine ecosystems in the Swiss Alps. Can. J. For. Res. 43: 901-910.

Ruel, J.C., Achim, A., Herrera, R.E., Cloutier, A., and Brossier, B. 2010. Wood degradation after windthrow in a northern environment. Forest Prod. J. 60(2): 200-206.

Russell, M., Woodall, C.W., Fraver, S., D’Amato, A.W., Domke, G., and Skog, K. 2014. Residence times and decay rates for downed woody debris biomass/carbon in eastern US forests. Ecosystems 17: 765-777. 
371 Russell, M., Fraver, S., Aakala, T., Gove, J., Woodall, C.W., D’Amato, A.W., and Ducey, M.J.

372 2015. Quantifying carbon stores and decomposition in dead wood: A review. For. Ecol.

373 Manage. 350: 107-128.

374 SAS Institute Inc. 2013. SAS/STAT® 9.4 User’s Guide. SAS Institute Inc., Cary, North Carolina, $375 \quad$ USA.

376 Sollins, P. 1982. Input and decay of coarse woody debris in coniferous stands in western Oregon 377 and Wahington. Can. J. For. Res. 12: 18-28.

378 Stokland, J.N., Siitonen, J., and Jonsson, B.G. 2012. Biodiversity in dead wood. Cambridge $379 \quad$ University Press, Cambridge, UK.

380 Venäläinen, M., Partanen, H. and Harju, A. 2014. The strength loss of Scots pine timber in an 381 accelerated soil contact test. Int. Biodeter. Biodegr. 86: 150-152.

382 Witomski, P., Olek, W., and Bonarski, J.T. 2016. Changes in strength of Scots pine wood (Pinus

383 silvestris L.) decayed by brown rot (Coniophora puteana) and white rot (Trametes 384 versicolor). Constr. Build. Mater. 102: 162-166.

385 Woodall, C.W., and Monleon, V.J. 2008. Sampling protocols, estimation procedures, and 386 analytical guidelines for down woody materials indicator of the Forest Inventory and 387 Analysis program. USDA, Forest Service, Gen. Tech. Rep. NRS-22. 
390 Table 1. Parameter estimates (with standard errors) and fit statistics for models relating strength 391 loss metrics $(y)$ to mass loss $(x)$, in the form $y=a \cdot x^{b}$. RMSE $=$ root mean square error.

\begin{tabular}{llcccc}
\hline \multirow{5}{*}{ Bending strength } & \multicolumn{1}{l}{$a$} & $b$ & $R^{2}$ & RMSE \\
\cline { 2 - 6 } & A. saccharum & $21.7(3.6)$ & $0.38(0.05)$ & 0.84 & 12.0 \\
& A. balsamea & $11.9(3.2)$ & $0.43(0.11)$ & 0.56 & 12.3 \\
& P. tremuloides & $9.6(2.3)$ & $0.56(0.06)$ & 0.87 & 10.9 \\
& Species pooled & $13.7(2.0)$ & $0.47(0.04)$ & 0.86 & 13.7 \\
& & & & & \\
Compressive strength & A. saccharum & $1.5(0.9)$ & $1.01(0.16)$ & 0.79 & 16.7 \\
& A. balsamea & $26.6(5.9)$ & $0.15(0.10)$ & 0.25 & 13.8 \\
& P. tremuloides & $5.3(2.4)$ & $0.69(0.12)$ & 0.77 & 16.6 \\
& Species pooled & $7.2(1.8)$ & $0.61(0.07)$ & 0.72 & 18.3 \\
& & & & & \\
Surface hardness & A. saccharum & $6.7(2.7)$ & $0.64(0.12)$ & 0.74 & 17.3 \\
& A. balsamea & $10.8(3.3)$ & $0.44(0.13)$ & 0.55 & 12.7 \\
& P. tremuloides & $4.7(1.5)$ & $0.70(0.09)$ & 0.86 & 10.3 \\
& Species pooled & $6.9(1.3)$ & $0.62(0.05)$ & 0.82 & 14.0 \\
\hline
\end{tabular}


394 Table 2. Pearson coefficients indicating the correlation among three strength metrics (bending 395 strength, compressive strength, and surface hardness) in dead woody material for each of the 396 three species tested.

\begin{tabular}{|c|c|c|c|c|c|c|}
\hline & \multicolumn{2}{|c|}{ A. saccharum } & \multicolumn{2}{|c|}{ P. tremuloides } & \multicolumn{2}{|c|}{ A. balsamea } \\
\hline & Bending & Comp. & Bending & Comp. & Bending & Comp. \\
\hline Compression & 0.79 & - & 0.89 & - & 0.59 & - \\
\hline Hardness & 0.86 & 0.87 & 0.90 & 0.87 & 0.53 & 0.61 \\
\hline
\end{tabular}

397

398 


\section{$399 \quad$ Figure Captions}

400 Fig. 1. Relationship between three strength-loss metrics and mass loss of decaying wood.

401 Colored dots and lines represent the three species tested (Abies balsamea = green, Acer

402 saccharum = blue, Populus tremuloides = red); the grey line represents pooled species data. $R^{2}$

403 values refer to pooled data. Model parameters for individual species are shown in Table 1.

404 Intercepts of the fitted curves are positive for all three metrics, meaning that strength is reduced

405 before any mass loss has occurred.

406

407

408 

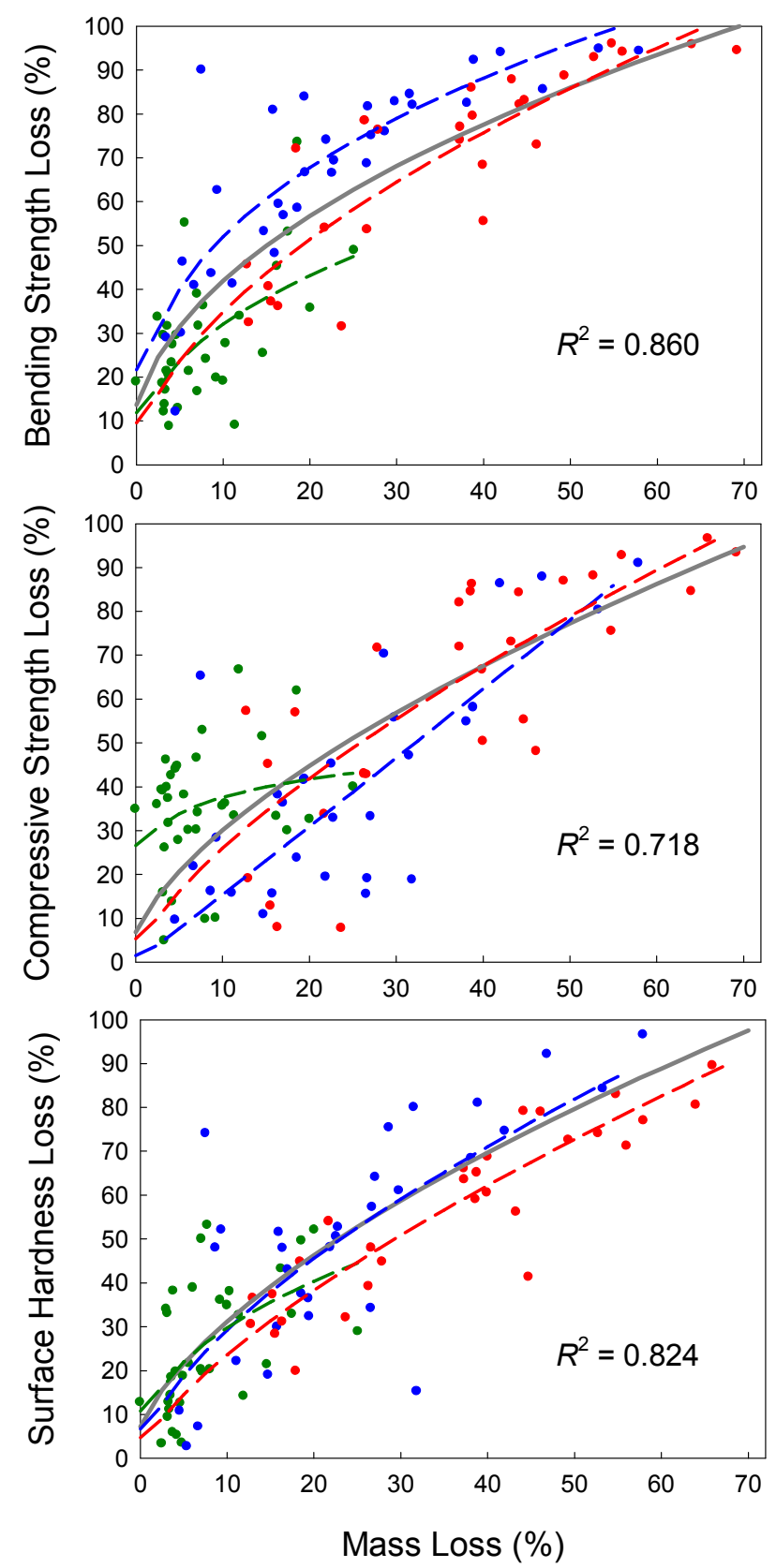

Fig. 1. Relationship between three strength-loss metrics and mass loss of decaying wood. Colored dots and lines represent the three species tested (Abies balsamea $=$ green, Acer 413 saccharum = blue, Populus tremuloides = red); the grey line represents pooled species data. $R^{2}$ 414 values refer to pooled data. Model parameters for individual species are shown in Table 1. Intercepts of the fitted curves are positive for all three metrics, meaning that strength is reduced 416 before any mass loss has occurred. 